\title{
External Migration of the Finns in the 1970's
}

By ALTTI MAJAVA

Ministry of Labour

\section{Post-war migration trends}

Emigration was on two occasions, during the last hundred years, a significant social phenomenon in Finland: before the First World War, and after the Second World War. Between 1880 and 1914 about 300,000 Finns settled in countries overseas, mainly in the United States. In the inter-war period, emigration from Finland was small because of the various obstacles (visas, residence and work permits etc.) to international labour mobility in most countries. Since the Second World War, nearly 500,000 Finns have emigrated, most of them to Sweden. Allowing for return migration, the net emigration was about 270,000 persons, equalling 5.5 per cent of Finland's present population (4.7 million).

In the post-war history of Finnish emigration, the year 1970 was notable, first for a culmination of the rising trend in emigration, and second for the introduction of accurate statistics on inter-Nordic migrants. Although data on emigrants in the 1950 s and 1960 s are virtually non-existent, it may be estimated that the number of emigrants and return migrants were by 5 -year periods as follows:

\begin{tabular}{|c|c|c|c|}
\hline & Emigrants & \multicolumn{2}{|c|}{ Returnees } \\
\hline $1946-1950$ & 40,000 persons & 8,000 & rsons \\
\hline $1951-1955$ & 65,000 & 22,000 & $»$ \\
\hline $1956-1960$ & 70,000 & 25,000 & $»$ \\
\hline $1961-1965$ & 85,000 & 32,000 & " \\
\hline $1966-1970$ & 155,000 & 53,000 & » \\
\hline $1971-1975$ & 70,000 & 75,000 & ” \\
\hline
\end{tabular}

The main destinations of the emigrants in the $1946-1975$ period were:

Sweden

Canada

Australia

United States

Other countries

Total

$\begin{array}{r}390,000 \text { persons } \\ 25,000 \text { " } \\ 18,000 \\ 15,000 \text { " } \\ 37,000 \text { " } \\ \hline\end{array}$

485,000 persons
( 80 per cent)

( 5 »)

$(4 \bowtie 》)$

$(3 \gg 》)$

( 8 " ) )

(100 per cent) 
Apart from Sweden, three countries may be singled out as significant destinations of Finnish emigrants since the Second World War. Canada was host country to several thousand Finnish emigrants annually in the 1950 s; since then, however, there have been only a few hundred emigrants to Canada per year. Emigration to Australia has twice (in 1958-59 and 1969-70) exceeded 2,000 persons per year; but since 1971 less than 500 Finns have moved to Australia each year. Emigration to the United States has been very stable at $300-700$ persons a year. In addition, emigration to Denmark, Norway, the Federal Republic of Germany and Great Britain deserve to be mentioned. As a rule, the number of emigrants to each of these countries has amounted to a few hundred per year.

The data on the Finnish emigrants are mainly based on the immigration statistics of the major countries of destination. While these data may be taken as fairly accurate, the data on returns are crude estimates because several immigration countries have kept no records of out-migrating Finns or such records have been deficient. Nevertheless, it may be estimated that nearly 85 per cent of the return migrants in 1946-1975 came back from Sweden (i.e. about 180,000 persons), while Australia, Canada and the United States contributed about 3 per cent each to the return flow. Thanks to the strong emigration at the end of the $1960 \mathrm{~s}$, return migration outnumbered the subsiding emigration in the early 1970 s.

After the culmination of Finnish emigration in 1970 the outflow decreased sharply, and it has since then been on the same level as in the 1950s. As emigration to countries outside Scandinavia has been almost negligible in the 1970 s, the dominant role of Sweden as host country has become even more pronounced. Although the expanding oil industry in Norway has emerged as a new attraction to certain categories of Finnish workers (welders and platers in particular), emigration to Norway has at least so far not increased markedly. Therefore, in describing recent trends of Finnish external migration, it is appropriate to concentrate on migrations between Finland and Sweden.

\section{Migrations between Finland and Sweden}

Apart from the early post-war years, the migrations between Finland and Sweden have taken place within the framework of the Common Nordic Labour Market. Its establishment in 1954 implied small changes in practice; in fact it was the formal confirmation of the free movement of labour that had been practised by some Nordic countries for several years. Thus, Sweden abolished the work permit for Nordic citizens already in 1943, and since the abolition of the visa requirement in December 1949 Finnish citizens have been able to enter Sweden without restrictions. In 1973 a supplementary agreement was concluded between Finland and Sweden to channel the migratory flows increasingly through the public employment service. 
Trends until 1970. - Research into migrations between Finland and Sweden before 1970 must be based on Swedish data only because, in $1954-69$, no relevant statistics concerning migrations to and from the other Nordic countries were collected in Finland. The introduction of the Nordic certificate of migration in October 1969 improved the quality of statistics on external migration in all the Nordic countries. The Swedish statistics on immigrants may be taken as fairly adequate, with the exception of the post-war years when refugees, »war children» etc. were registered even several years after the actual entry. However, the Swedish statistics have been deficient due to the fact that a considerable part ( $20-30$ per cent) of the return migrants have failed to report their departure to the Swedish population register. Hence, the transfers to the »recidence unknown" register must be taken into account also to get a true impression of actual returns.

Data on the migrations between Finland and Sweden from 1946 to 1975 are given in Figure 1. As seen from it, the migration from Finland to Sweden increased without interruption from 1946 to 1951. Thereafter emigration to Sweden displayed a distinct cyclical pattern, with troughs occurring more regularly than peaks. In the 1950 s emigration of Finns to Sweden was rather stable but in the 1960 s a steeply rising trend and widening variations were discernible. In the years 1969 and 1970 emigration from Finland to Sweden was

F ig u re 1. Migrations between Finland and Sweden in 1946-1975 according to Swedish statistics, and estimated actual migratory flows

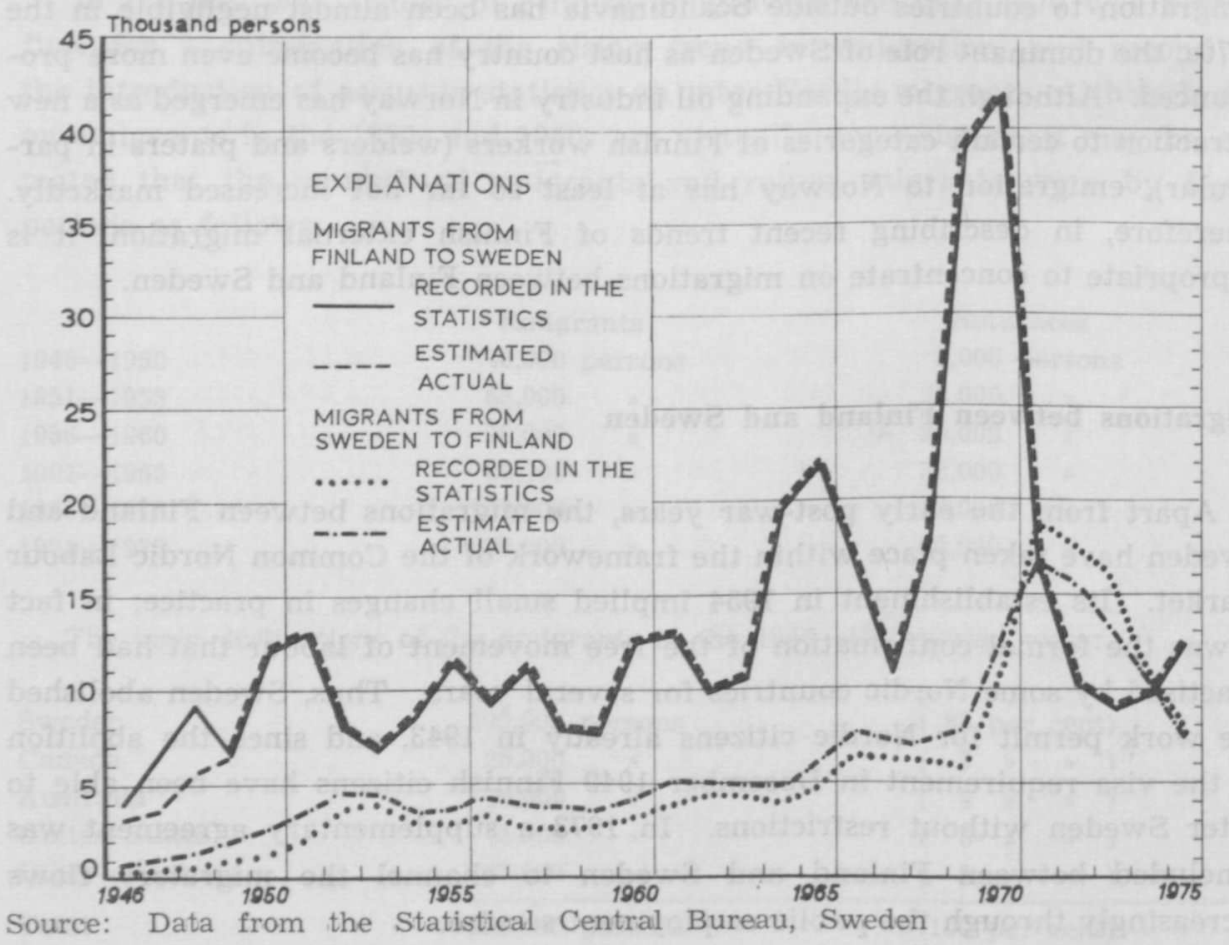


singularly strong; it even caused the population of Finland to decline. In 1971 emigration fell abruptly, and it has since then been rather stable, around 10000 persons a year.

As far as returns are concerned, fairly accurate estimates may be made for the years $1955-65$ only because transfers to the »residence unknown register» cover adequately the years $1957-67$. Hence, somewhat arbitrary methods must be employed to estimate the number of unreported returns for the years before 1955 and after 1965 . The estimates concerning total return migration indicate that returns were comparatively few in $1946-50$, in the 1950 s returns corresponded to about 40 per cent and in the 1960 s to nearly 35 per cent of the current emigration.

Developments since 1970. - Thanks to the Nordic certificate of migration, which was taken into use in all the Nordic countries in October 1969, data are available on migrations between Finland and Sweden in both the countries concerned since 1970. The data concerning the annual numbers of migrants are presented in Table 1. However, the Finnish statistics on the emigrants and return migrants in 1975 are not yet (October 1976) available due to delays caused by the reorganisation of the vital statistics production put into effect on January $1,1975$.

In principle, the national data relating to the same migration streams should tally with each other. Nevertheless, it took some time for the Finnish and the Swedish data to become reasonably congruent; one of the main reasons for this was belated registration of migrations that had in fact taken place before October 1969. Thus, the data on emigration from Finland have tallied fairly well from 1972 onwards, whereas consistency in regard to return statistics was not reached until 1974. As for net migration, the national statistics have yielded even significantly divergent results; in 1972 the discrepancy exceeded 2,000 persons. In all likelikood the Swedish statistics have been more accurate than the Finnish ones, although the Swedish data on returns on 1970-73 may have been somewhat too high (i.e. they include persons who had left Sweden before 1970).

$\mathrm{T}$ a ble 1. Migrations between Finland and Sweden in 1970-1975 according to the Finnish and the Swedish statistics (number of persons)

$\begin{array}{crrrrrr}\text { Year } & \begin{array}{c}\text { From Finland to Sweden } \\ \text { Finnish } \\ \text { data }\end{array} & \begin{array}{c}\text { Swedish } \\ \text { data }\end{array} & \begin{array}{c}\text { Finnish } \\ \text { data }\end{array} & \begin{array}{c}\text { Swedish } \\ \text { data }\end{array} & \begin{array}{c}\text { Balance for Finland } \\ \text { Finnish } \\ \text { data }\end{array} & \begin{array}{r}\text { Swedish } \\ \text { data }\end{array} \\ 1970 & 39745 & 41479 & 8910 & 10961 & -30835 & -30518 \\ 1971 & 15535 & 16601 & 16455 & 18712 & 920 & 2111 \\ 1972 & 10254 & 10313 & 15460 & 17918 & 5206 & 7283 \\ 1973 & 8635 & 9013 & 14402 & 15918 & 5767 & 6905 \\ 1974 & 10070 & 9705 & 10474 & 10980 & 404 & 1275 \\ 1975 & \ldots & 12139 & \ldots & 7705 & \ldots & -4434\end{array}$


As already noted, emigration from Finland culminated in 1970, when about 40,000 Finns left for Sweden. In 1971 the number of emigrants was still considerable $(16,000)$ but remained then fairly stable at $9,000-10,000$ for the next three years. In 1975, however, there was a significant (26.4. per cent) increase in emigration: from 9,601 to 12,139 . Taking into account the timelags of registration, the real increase might have been even greater. Nevertheless, the number of emigrants probably did not exceed 13,000 persons in 1975.

The emigration wave of 1969 - 70 generated a sizeable return flow for 197173 , when the returns exceeded 15,000 per year. Still in 1974 there were about 10,000 returnees but barely some 7,000 in 1975 . After the heavy losses in 196970 (about 30,000 persons a year, i.e. 0.6 per cent of Finland's population), the migratory flows were near a balance in 1971. In 1972 and 1973 a return surplus of some 6,000 a year prevailed, and in 1974 the currents were again in balance. In 1975 the net emigration, which was recorded at 4,434 persons, amounted in reality to $5,000-6,000$ persons. - It seems at the present writing (October 1976) that the net loss in 1976 may amount to $8,000-9,000$ persons, resulting from the emigration of some $15,000-16,000$ Finns while returns may fall short of 7,000 .

Some findings concerning return flows. - The return surplus that prevailed from May 1971 to August 1974 was a consequence of the exceptionally strong emigration in 1969-70 and its ebbing in the early 1970s. Hence, the crude figures do not reflect the actual return propensity of the emigrants who left Finland during the period under review. This kind of information may be obtained from the Statistical Central Bureau of Sweden (SCB), where data have been produced since 1968 on the depletion of annual chorts of immigrants due to return migration. The findings concerning Finnish citizens since 1970 are summarised in Figure 2.

The cohorts of Finnish emigrants entering Sweden in 1970 through 1973 show a remarkably stable pattern of returns. Roughly $10-12$ per cent of male migrants, and about $8-10$ per cent of female migrants, returned already during the same calendar year in which they were registered as immigrants, while about 18-21 and 14-16 per cent, respectively, returned during the following calendar year. Another 10 per cent of the male migrants returned during the second full calendar year after immigration, and $7-8$ per cent of the female ones. Thus, of about $40-45$ per cent the male Finnish migrants entering Sweden in 1970-1973, and 30-35 per cent of the female ones, seemed to return in less than three years' time. As for the immigrants registered in 1974, data on returns are available only for two calendar years, and as for the 1975 cohort barely for that year. These limited data (in Figure 2) suggest a decrease in the propensity to return. As also returns among the previous cohorts were in 1975 less frequent than returns in the corresponding phases earlier, the decline in return migration was most probably due to the deteriorating employment situation in Finland. 
Figure 2. Returns among emigrant cohorts of 1970 to 1975 , in per cent of each cohort by calendar years after emigration
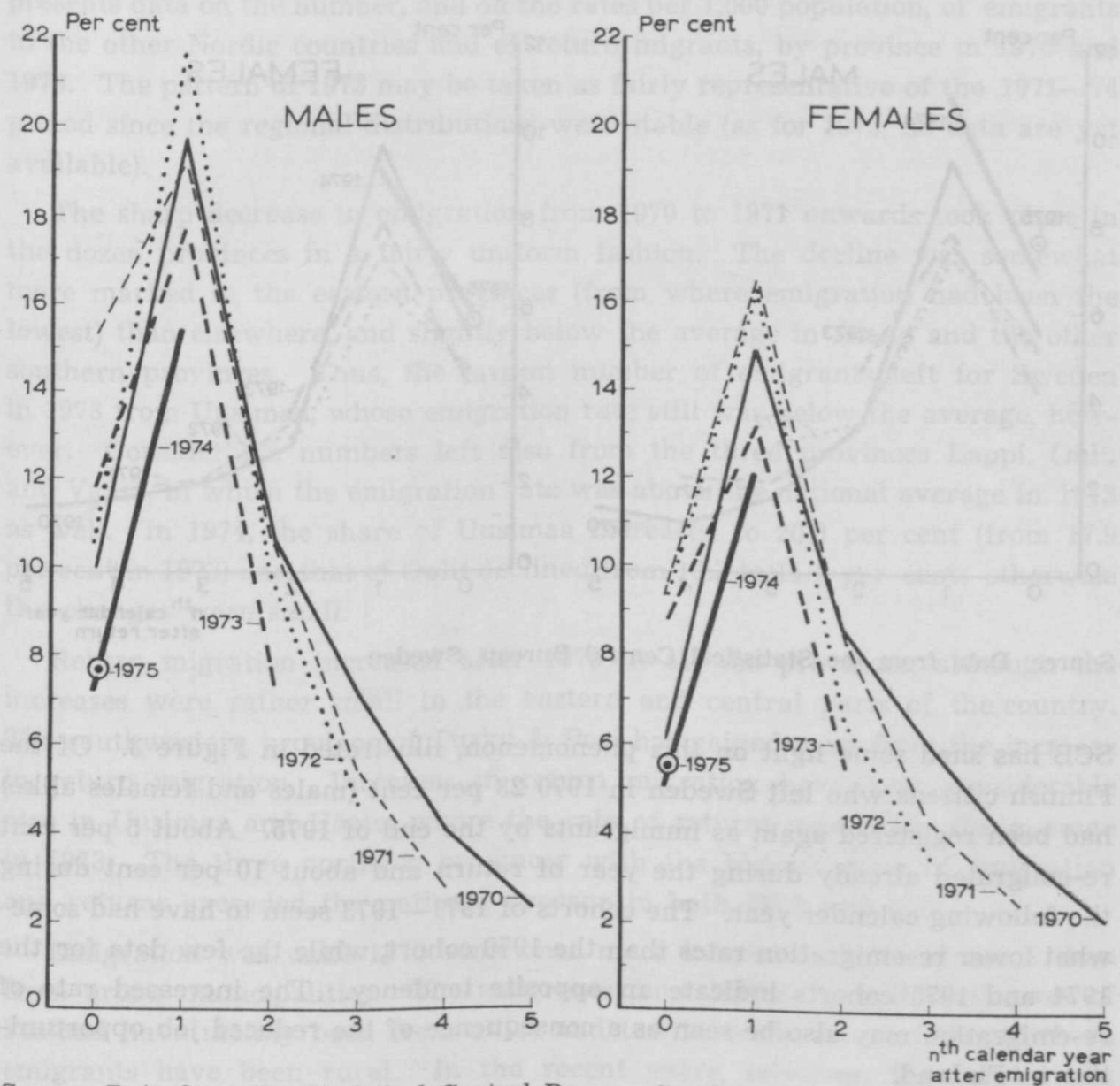

Source: Data from the Statistical Central Bureau, Sweden

Mr. Rolf Olofsson, of the SCB, has analysed the data on return migration in some depth and found that the propensity to return varies a great deal by age. Returns are most common among those, males in particular, who immigrate to Sweden at the age of $15-24$ years. One reason for the high return rate among young males is the military service. On the other hand, returns are comparatively rare among those who move to Sweden at the age of $10-14$ years; it is likely that families with school-age children stay in Sweden to a greater extent than other migrant categories.

Re-emigration. - It is well-known that some return migrants do not repatriate successfully and emigrate again. Until now there have been available no data to estimate the extent of re-emigration; nevertheless, "guesstimates" ranging from a quarter to a third have been mentioned. Recently the 
Figure 3. Re-emigration among returnee cohorts of 1970 to 1975 , in per cent of each cohort by calendar years aftern return
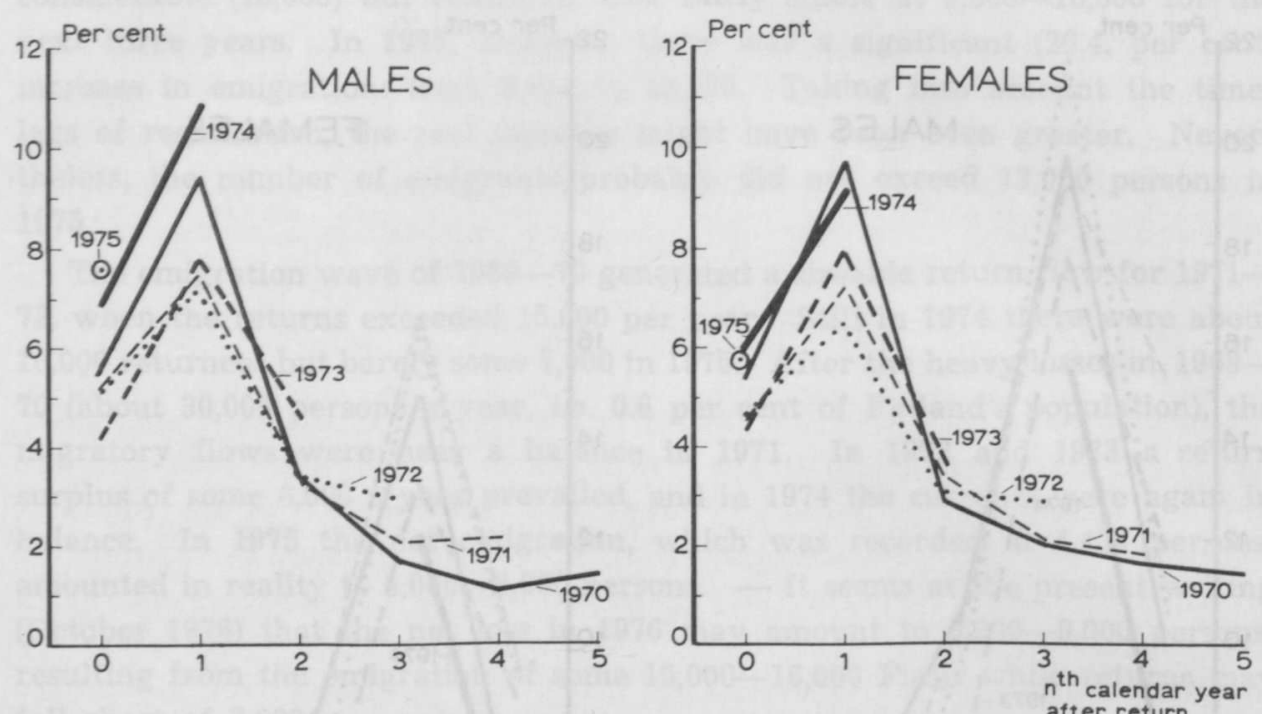

Source: Data from the Statistical Central Bureau, Sweden

SCB has shed some light on this phenomenon, illustrated in Figure 3. Of the Finnish citizens who left Sweden in 197023 per cent (males and females alike) had been registered again as immigrants by the end of 1975 . About 5 per cent re-emigrated already during the year of return and about 10 per cent during the following calender year. The cohorts of $1971-1973$ seem to have had somewhat lower re-emigration rates than the 1970 cohort, while the few data for the 1974 and 1975 cohorts indicate an opposite tendency. The increased rate of re-emigration may also be seen as a consequence of the reduced job opportunities in Finland.

\section{Characteristics of migration}

External migration is unevenly distributed, e.g. by regions, by sex and age, by occupations etc. Certain differentials have been affected by the changes in the volume of migration while others seem to be rather stable.

Regional distribution. - Emigration rates have been the highest in the north and west of Finland; until the late 1960s, it was from the Swedish-speaking, western provinces (Åland and Vaasa) that emigration was the heaviest. From 1968 onwards, however, the regional distribution shifted towards the north: nearly 40 per cent of the emigrants came from the two northernmost provinces (Lapland and Oulu), whose population is only 13 per cent of the total. During the three years, 1968-1970 the net emigration loss of Lapland amounted to 
roughly 6 per cent and that of the Oulu province to almost 4 per cent (the national average was 2 per cent). To illustrate the regional pattern, Figure 4 presents data on the number, and on the rates per 1,000 population, of emigrants to the other Nordic countries and of return migrants, by province in 1970 and 1973. The pattern of 1973 may be taken as fairly representative of the $1971-74$ period since the regional distributions were stable (as for 1975, no data are yet available).

The sharp decrease in emigration from 1970 to 1971 onwards took place in the dozen provinces in a fairly uniform fashion. The decline was somewhat more marked in the eastern provinces (from where emigration had been the lowest) than elsewhere, and slightly below the average in Alland and the other southern provinces. Thus, the largest number of emigrants left for Sweden in 1973 from Uusimaa, whose emigration rate still was below the average, however. Considerable numbers left also from the three provinces Lappi, Oulu and Vaasa, in which the emigration rate was above the national average in 1973 as well. In 1974, the share of Uusimaa increased to 20,3 per cent (from 17.9 per cent in 1973) and that of Oulu declined from 15.3 to 11.1 per cent; otherwise the changes were small.

Return migration increased after 1970 in all the provinces, although the increases were rather small in the eastern and central parts of the country. The southwestern province of Turku \& Pori has gained most from the increase in return migration. Increases in return migration have been considerable also in Uusimaa and Häme, where the rate of returns was below the average in 1973. The three northern provinces with the highest rates of emigration and returns exceeded the national average in both 1970 and 1973.

Emigration was until 1973 somewhat more intense from rural areas than from urban municipalities. The emigrants from the south and south-west of Finland have mainly been from cities and towns, while most of the northern emigrants have been rural. In the recent years, however, the rural-urban differential has been diminishing: the percentage of the urban emigrants was about 45 in 1970, 47 in 1971 and 49 in 1972; for comparison, nearly 55 per cent of the Finnish population lived in cities and towns in 1972. In 1973, the differential disappeared altogether since 56 per cent of emigrants came from urban municipalities. As for return migration, the share of urban centres has been somewhat smaller than in emigration since 1971; in 1970 cities and towns received 47 per cent of return migrants and in 1973, for example, 53 per cent. Return migration thus reflects the pattern of earlier emigration: according to a study concerning return migrants about 70 per cent of the respondents had returned to the municipality of departure.

Net migration, which showed great regional variations in 1970, was remarkably uniform in 1973. Excepting the small Swedish-speaking province of Åland, the net migration gain was rather close to the national average in all the provinces. 
Figure 4. Emigration, return migration and net migration by provinces in 1970 and 1973
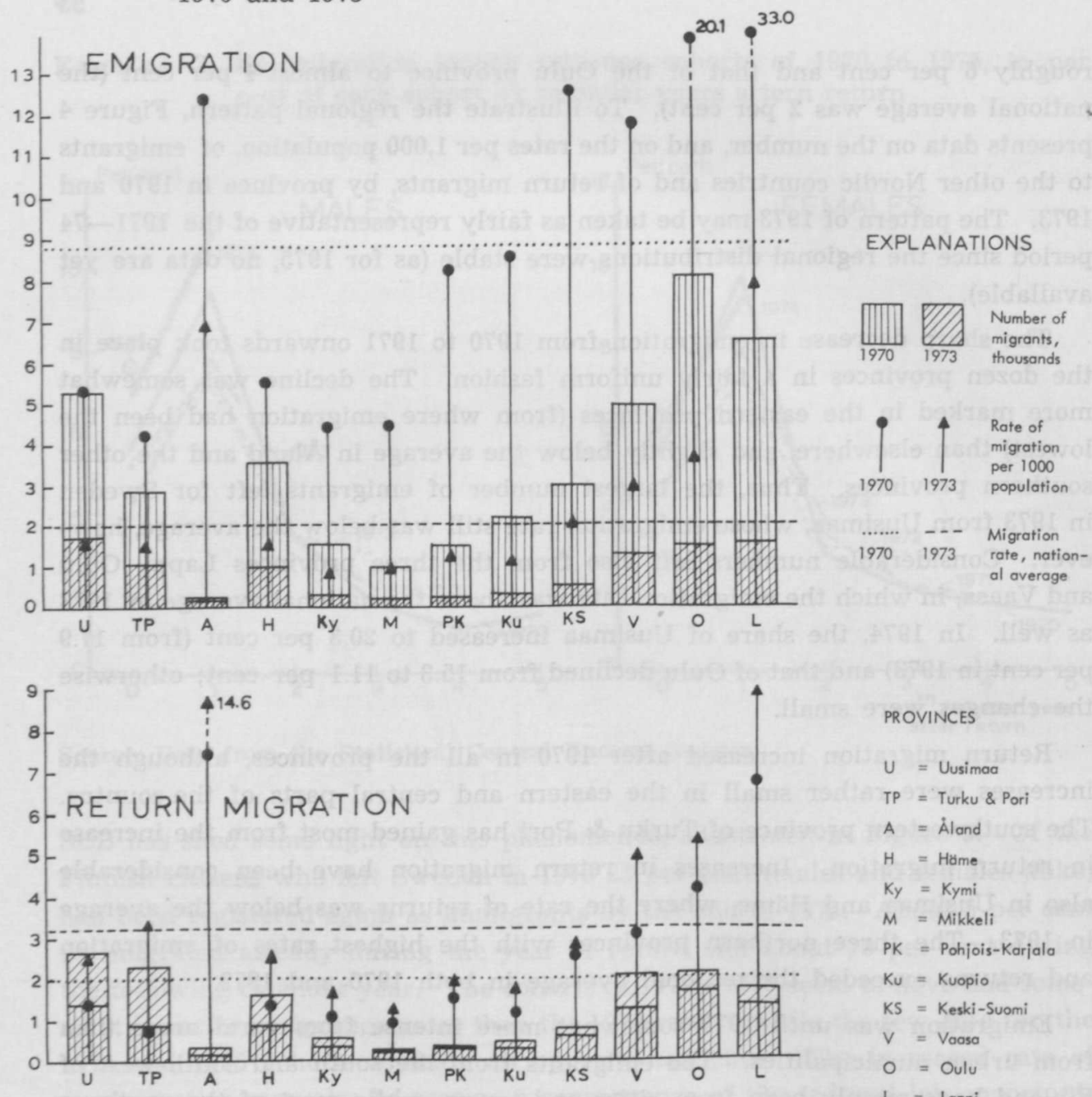

PROVINCES

$U=$ Uusimac

$T P=$ Turku \& Pori

$A=$ Alland

$H=$ Häme

$K_{y}=K_{y m i}$

$M=$ Mikkeli

PK = Pohjois-Karjala

$\mathrm{Ku}=$ Kuopio

$\mathrm{KS}=$ Keski-Suomi

$V=$ Voosa

$0=$ Oulu

$L=L a p p i$
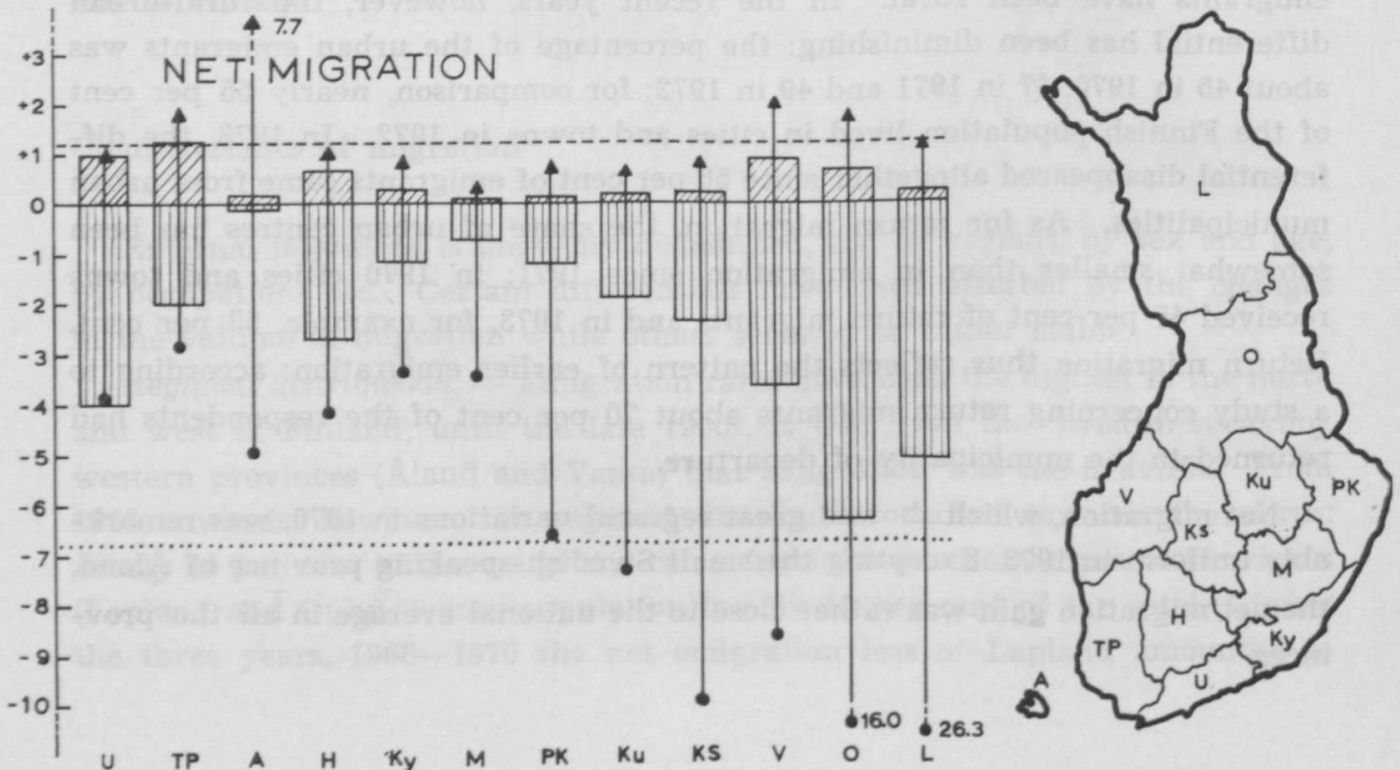

Source: Data from the Central Statistical Office, Finland 
The sex and age composition of the emigrants and the return migrants in 1973 is depicted in Figure 5. For comparison, the age "pyramids" of the Finnish citizens resident in Sweden and the total population of Finland are shown also. The distributions are comparable; the area within each pair of curves equals 100 per cent.

The shapes of the four age spyramids» differ substantially from each other. The structure of the emigrants is the most extreme, with distinct »bulgings» in the age group 20-24 years, and constrictions in the age group 10-14 years. The structure of the return migrants resembles that of the emigrants on the male side with allowance for the somewhat higher mean age of the former. On the female side, however, the age distribution of the return migrants resembles more the structure of the Finns resident in Sweden, with the exception of school-age children. At the age of $20-30$ years females seem to have a lesser propensity to return than males; one reason for it is that females marry Swedes more frequently than men. - The demographic structure of the Finns in Sweden is not quite so peculiar because of the smoothing effect of several successive cohorts of migrants. Also the population of Finland deviates markedly from the normal pyramid pattern mainly because of great variations in the number of births during the past several decades.

In 1973 , as in $1971-72$, about 53 per cent of the emigrants were men, i.e. a somewhat smaller proportion than during the peak years of emigration: in 1969-70 as much as 56 per cent of the emigrants were men. In the return flow the excess of males - which was very pronounced in 1970 and 1971: 61 per cent - levelled off slightly by 1973 when 58 per cent of the return migrants were males.

Fig u re 5. Sex and age structure, in per cent, of Finnish emigrants to Sweden, Finnish citizens resident in Sweden and the population of Finland, in 1973

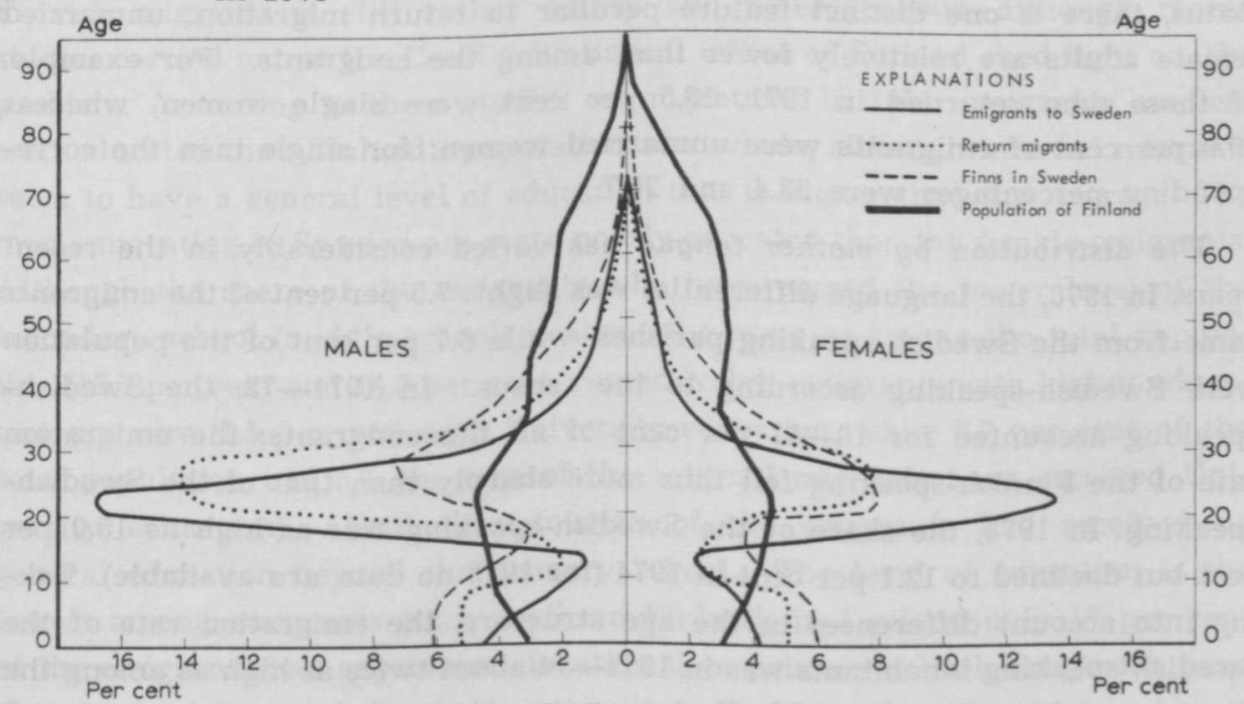

Source: Data on the migrants from the Statistical Central Bureau, Sweden 
Between 1972 and 1973 no appreciable changes in the age structure could be discerned. Compared to 1970 , however, there were fewer children among the emigrants in 1973 (18 per cent under 14 as against 21 per cent in 1970) and youngsters of $15-19$ (17 and 20 per cent, respectively). On the other hand, the share of the age group 25-29 years was greater in 1973 than in 1970: 16 and 10 per cent, respectively. In the other age groups the distribution was about equal in both years.

According to the data available for 1970, rural emigrants are somewhat younger than the urban emigrants. Regional data do not reveal any major differences in the age structure, although emigrants from eastern Finland seem to be somewhat older than emigrants from other parts of the country; moreover there were remarkably few child emigrants from Åland (11 per cent) in 1970.

Family Composition. - Most emigrants are unmarried. In 1970, for example, 64 per cent of the emigrants were unmarried; and an age standardisation suggests that there were almost 35 per cent more unmarried persons among the emigrants than in the total population of Finland, on the average. It seems that the ratio of single people is particularly high among emigrants from the northern and eastern parts of Finland. Unmarried people predominate among emigrants from rural areas to an even larger extent than among those who move from urban centres.

According to the Swedish statistics, 29 per cent of Finnish immigrants in 1970 were married, but in 1971 the corresponding percentage declined to 24 . At the same time, the share of children under 18 shrank from 28 to 23 per cent. As far as unmarried adults were concerned, single men accounted for 26 per cent of all Finnish immigrants entering Sweden in 1970 and 29 per cent in 1971: for single women the corresponding percentages were 14 and 19. Emigration of families has thus become less frequent since 1970. In regard to the marital status, there is one distinct feature peculiar to return migration: unmarried female adults are relatively fewer than among the emigrants. For example, of those who returned in 1971, 13.5 per cent were single women, whereas 19.0 per cent of emigrants were unmarried women; for single men the corresponding percentages were 33.4 and 28.7 .

The distribution by mother tongue has varied considerably in the recent years. In 1970, the language differential was slight: 7.5 per cent of the emigrants came from the Swedish-speaking parishes, while 6.7 per cent of the population were Swedish-speaking according to the census. In 1971-72, the Swedishspeaking accounted for 10-11 per cent of all the emigrants; the emigration rate of the Finnish-speaking fell thus more sharply than that of the Swedishspeaking. In 1973, the share of the Swedish-speaking was as high as 15.0 per cent but declined to 12.1 per cent in 1974 (for 1975 no data are available). Taking into account differences in the age structure, the emigration rate of the Swedish-speaking inhabitants was in 1971-74 about twice as high as among the Finnish-speaking Finns. - Of all the return migrants, between 9.1 and 11.7 
per cent moved to the Swedish-speaking parishes in 1970 - 74 (except for 1973, when the share was 14.4 per cent).

Occupational structure. - Data concerning the occupational structure of emigrants are scanty. According to the few investigations made in the recent years, about a fifth of the emigrants have, before departure, worked in agriculture and forestry, $25-40$ per cent in manufacturing industries, and $20-30$ per cent in service occupations. In Sweden $65-75$ per cent work in manufacturing industries and 15-20 per cent in the service sector. Most return migrants seem to change the type of activity again since their occupational composition after the return resembles that prevalent before their departure for Sewden, according to a study conducted in $1972-73$ by Sirkka-Liisa Heikkinen on return migrants of 1968-69 and 1971. The most conspicuous difference in the distributions before and after the stay in Sweden refers to the primary sector: more than one half of those who had worked in agriculture and forestry before emigration chose some other activity - usually in the manufacturing industry or a service occupation - after the return.

According to the same study there is a heavy concentration of migrant men in the metal industry in Sweden; and also after return it is the most commonly chosen field of activity. Also rather high a proportion (16.6 per cent) of women work in the Swedish metal industry, but most of them move to other fields in Finland. Of those who are in Finland both before and after the stay in Sweden outside the labour force, few are not gainfully employed while in Sweden. Further work is needed to find out how many change their industry and occupation in connection with migration to and from Sweden and between which industries in that case.

Educational structure. - Information on the educational structure of the Finnish migrants is still rather scanty and heterogeneous, although recent studies carried out at the Central Statistical Office of Finland shed light on the problem. According to these studies on migrations in 1971, emigrants are less well educated than Finland's population as a whole, although internal migrants seem to have a general level of education that is higher than the average. The men emigrating to Sweden are more poorly educated than the female emigrants. Although the share of the emigrants who have passed the lower level of the secondary school (middle school) is about the same as among the total population (15.7 per cent and 14.3 per cent, respectively), emigrants with higher education are rare (1.5 per cent with University education, while 2.7 per cent of the total population and 5.7 per cent of the internal migrants have received University education). About three-fourths of the emigrants had received no general education beyond the primary school. The level of education is the lowest among emigrants from northern Finland; in Lapland only 17 per cent of the emigrants had any other education than primary school. Emigrants have also received less vocational education than Finns on the average. 


\section{Causes of migration}

The causes of emigration and return migration have not yet been exhaustively explored, although various studies made in the recent years have thrown light on the migrants' personal motives and on certain institutional and structural factors. The latter are of prime importance since they are preconditions for significant migratory flows; i.e. they influence, as forces of push and pull, individual decisions to migrate. In Finland's case the rapid structural change in the economy during the post-war decades may be taken as the major cause of emigration pressure, while persistent labour shortages and higher wages in Sweden have acted as the main attractions. Since there were no legal barriers to mobility thanks to the Common Nordic Labour Market, considerable migration flows ensued, especially as also the geographic, social and cultural hindrances are relatively minor; the only real obstable for the Finnish-speaking is the language barrier.

Particularly in the northern and eastern provinces of Finland the persistent structural unemployment has counted as an important »repellent» force. Accordingly, the bulk of the emigration has been from areas of underemployment, low wages, high local taxes, etc. These persistent repellents have taken their effect when the Swedish reception capacity has been high - during booms. According to several studies a minority (10 to 25 per cent) of the emigrants have been actually unemployed at the time of departure. It is the threat of unemployment that has caused many people to break up from their homesteads and to move to Sweden in search of secure employment. One of the factors maintaining the threat of unemployment is, in turn, the out-migration that weakens the base for economic and social development in the areas of departure.

Factors hampering internal migration have also contributed to emigration. Housing shortages have prevented many from moving to the south and southwest of Finland, leaving Sweden as the only alternative. Another reason has been the higher demand for unskilled labour in Sweden than in Finland. Sweden's post-war labour market was characterised by a low level of unemployment and a high but varying level of labour demand. Therefore, emigration to Sweden has varied in accordance with the Swedish business cycle and employment situation with a delay of six months or so. These fluctuations have been quite regular; in the sixties, peaks of emigration occurred in 1960-61, $1964-65$ and 1968-70. After 1970, emigration fell off largely as a result of the decreased demand for labour in Sweden; contrary to previous experience it did not rise again in 1973-74, although the business activity revieved in

Sweden. - On the other hand, no comparable correlation can be discerned between migrations and the Finnish labour market.

Emigrants can roughly be divided into two groups: the "attracted" and the "forced". The former are primarily attracted by the higher wages and living standard in Sweden, the latter mostly driven out by unemployment, loss of 
livelihood in the case of farmers and small shopkeepers, and growing social insecurity in the areas of departure.

Many of the emigrants to Sweden have been rather too optimistic about the standard of living there, especially during the late $1960 \mathrm{~s}$. They were then dazzled by the money - particularly after the Finnmark was devaluated by 31 per cent in 1967. In fact, after higher prices and taxation had taken their toll, the average industrial worker in Sweden had in 1971-75 a purchasing power that was about a fifth higher than in Finland. In the case of women the difference is somewhat greater, and in the case of the unskilled as well; wage differentials are smaller in Sweden than in Finland. Recent studies indicate that notions about actual earnings differentials have become more realistic in the 1970 s.

As for the personal motives for emigration, several studies reveal a roughly similar picture. Thus, it was found in the study on return migrants by Mrs. Sirkka-Liisa Heikkinen, of the Ministry of Labour, that 36 per cent of the respondents could, on the basis of the reasons given for emigration, be classified as »forced emigrants» ( 25 per cent had been actually unemployed, and 11 per cent had experienced the risk of acute lay-off), while 21 per cent were attracted by the higher wages and 10 per cent by better employment in Sweden; 11 per cent sought adventures and change of atmosphere; 8 per cent had training and self-development in mind, and 7 per cent wanted to join their relatives and friends; 8 per cent gave other or no reason for emigrating.

Whereas two-thirds of the emigrants moved to Sweden for mainly economic reasons, the primary reasons for return were non-economic according to Heikkinen's study: 36 per cent of the respondents stated attachment to Finland (such as relatives and friends, nostalgia for the home country and region, and children's education) as the main cause of return; adjustment problems (language difficulties, boredom, illness) accounted for 14 per cent, economic opportunities in Finland for 14 per cent, economic difficulties in Sweden for 6 per cent of the main reasons given, while 17 per cent had moved to Sweden only temporarily and 11 per cent gave other or no reason for their return.

For return migration, too, there are social factors influencing the individual decisions. A significant precondition for the increased return migration in the recent years has been the improved employment situation in Finland, and the enlarged housing construction another. Also labour market training and various measures to facilitate return migrants' readjustment (e.g. improved information, special tuition to school-children having language problems) may have had some effect.

\section{Manpower recruitment}

In 1954 the four Nordic countries (Denmark, Finland, Norway and Sweden) concluded an agreement establishing the Common Nordic Labour Market. Accordingly, the citizens of these countries may settle and take up employment 
anywhere in Scandinavia without special permits, and each Nordic state treats citizens from the other Scandinavian countries like it treats its own citizens. The agreement provides, further, that the leading labour market authorities cooperate in order to channel the greatest possible part of the inter-country migration of labour through the Public Employment Service and that the free mobility of labour be beneficial to each of the countries. Nevertheless, most Finnish migrants have in reality moved to Sweden and sought work there either on their own or with the help of relatives and friends. Such a spontaneous migration has given rise to various problems for authorities in both countries and, not least, for the migrants themselves. Therefore, the labour market authorities and organisations in Finland and Sweden concluded a supplementary, bilateral agreement to channel the migration of labour between the two countries through the Employment Service, which agreement came into force on July 1, 1973.

In accordance with that agreement, the Employment Service staff dealing with inter-Nordic migrations was strengthened considerably, specific information drives were launched, statistics were improved etc. The information at hand indicates that the application of the 1973 agreement met with considerable initial success: a clearly increasing proportion of migrant workers, particularly males, secured work in Sweden through Public Employment Service (PES). Thus, towards the end of 1973 about 40 per cent of the job-seeking male emigrants got referrals to work in Sweden through the Finnish PES (in 1972 the proportion was rather below than above 20 per cent). During 1974 the proportion increased further, to about 50 per cent. In 1975, however, this trend was broken: at most 45 per cent of the male migrant workers secured work in Sweden through the Finnish PES.

The 1973 agreement stipulates that if a newly arrived immigrant has not contacted the PES in the home country he must get in touch with the local employment exchange before he is hired. Taking into account the cases of this category, about 70 per cent of the job-seeking Finnish men contacted the PES either in Finland or Sweden in connection with emigration in 1974. This proportion was appreciably lower in 1975, rather below than above 60 per cent.

Female migrants use the PES to a much smaller extent than men. As far as married women are concerned this is understandable: the family may need to adjust itself in the new environment before the mother starts working outside of the home. It is disquieting that at most a fifth of the unmarried women who move from Finland to Sweden seek and secure work through the PES.

During 1975 there were nearly 3,900 placements of Finnish emigrants by the Finnish and Swedish PES. In 20 per cent of the cases the Finnish PES referred the job seeker to a named employer in Sweden and in 51 per cent to a named employment exchange office, while in 29 per cent the placement was made by the Swedish PES. The available data suggest that when a Finnish woman seeks work in Sweden through the Finnish PES she is referred to a named employer more often than a male job seeker. On the other hand, unmarried 
men are more inclined than other migrant groups to contact the PES not until in Sweden. Direct placements by the Finnish PES to named employers are rare for emigrants above 45 years of age, and for young job seekers as well. Direct placements are most common (about a third of the PES placements) from Lapland and Helsinki Labour District, and virtually none from Central and Eastern Finland.

In the $1960 \mathrm{~s}$, there were numerous reports on unauthorised recruitment activities by Swedish firms. These activities were suppressed through the concerted action by the Finnish and the Swedish labour market authorities, and for several years now cases of open private recruitment have been rare. On the other hand, informal recruitment by Finns employed in Sweden may, during holiday seasons in particular, be of considerable importance even at present.

\section{Consequences of migration}

Emigration and return migration have significant consequenses for not only the migrants but also the country and region of departure, and the country and region of arrival as well. In the present context, only consequences for Finland and regions of departure, and for the migrants, will be considered. Even in these cases the consequences are not yet fully explored; the research that is underway may result in a more nuanced picture about the long-term implications in particular.

Demographic consequences. - The most conspicuous consequence of emigration for Finland is the loss of people. In 1946-1975 the estimated total net emigration to Sweden was about 205,000 persons $(192,000$ since 1950$)$, which correspond to 4.3 per cent (4.0 per cent) of Finland's population at the end of 1975 . Thus, if the external migration to and from Sweden had been in balance, Finland's population had been nearly 4.9 million at the end of 1975 .

External migrants are unevenly distributed by age and other characteristics, as shown above. Migrants are in the active family-building age, and hence a considerable number of children are born to Finnish citizens abroad. Hence, if the return migration had matched the emigration flow, a part of the children born abroad had in fact been born in Finland. Consequently, a balanced external migration had resulted in a somewhat larger population total than the present one and the total emigration deficit combined.

The indirect consequences for Finland's (and Sweden's) population development are harder to assess. They are not limited to fertility and mortality. Also the marriage pattern is affected (there would have been less mixed marriages) as well as divorces. If there had been no opening for emigration, many emigrants had moved from their domicile to other parts of Finland.

A notable consequence of the Finnish emigration has been the fact that a new Finnish (partly Swedish-speaking) minority has emerged in Sweden in the recent decades. According to the 1970 census of Sweden there were 207,500 Finnish citizens and 235,500 persons born in Finland. Due to return surplus 
and naturalisations the number of Finnish citizens in Sweden declined to 188,000 in 1975. Nevertheless, if also children born to persons of Finnish origin are taken into account, the Finnish immigrant population continued to grow in the 1970 s, numbering more than 300,000 persons in 1975.

Other consequences. - In regard to the other direct effects of emigration, it was still in the 1960 s believed also in Finland that emigration would reduce unemployment. Later studies have, however, established that the unemployment reducing effects have been small and of short duration. Most emigrants have not been unemployed at their departure, and in many cases emigrants particularly those working as farmers, shopkeepers etc. on the verge of unprofitability - have not been replaced by unemployed workers, either. In contrast, emigration has depleted manpower resources and is thus, as a longer-term effect, one of the causes of the recurrent labour shortages. Nevertheless, since a part of emigrants have been unemployed, also the direct expenditures on public works, unemployment benefits etc. have been reduced, although this effect has been rather marginal in relation to all the repercussions of emigration.

Another direct effect of emigration is the loss of human capital. In other words, the returns in Finland to expeditures invested in a Finn's upbringing and education are smaller than otherwise, when the emigrant spends a considerable part of his productive life abroad. According to a study made by Mr. Veikko Savela at the Ministry of Labour the cost of upbringing and educating a child up to the age of 16 amounted in 1973 to $104,000 \mathrm{Fmk}$ (about 25,000 US dollars), on the average (about half of this is borne by the parents, the rest by the state and the municipality). Hence, since over 110,000 Finns are at present employed in Sweden and perhaps $20,000-30,000$ in other countries, it may be concluded that the total human investment in Finns working abroad amounts to the same order of magnitude as an annual state budget of Finland.

Furthermore, emigration implies an immediate reduction of income, purchasing power and taxes in the country of departure, which effects and their repercussions are most severely felt in the regions of considerable out-migration.

The indirect effects of emigration on the localities of departure entail changes in the marketing mechanism, age structure and birth rate, the public and commercial services available to the inhabitants, and in local taxation.

Indirectly, emigration increases unemployment and reduces incomes in the areas of departure. It cuts the total and the per-capita income of the population, which decreases the demand for labour and increases unemployment. So emigration maintains emigration pressure and thus aggravates the problems of the underdeveloped areas.

The effects on the age structure are clearly unfavourable. The ratio of the productive population shrinks and that of the unproductive, especially the old, increases. This again reduces per-capita income and raises per capita costs, thus augmenting taxes. The highest local taxes in Finland are as a rule in the municipalities with the highest rate of out-migration.

For the individual worker the freedom of movement within the Common 
Nordic Labour Market is, at least in principle, generally positive. Thus, the individual is in a position to take an unrestricted look at labour market three to four times as large as that of his own country. He may obtain an extended education with broader vocational specialties in the larger area. He may acquire occupational skills which will be available to him throughout his working life, even if he should in due course return home. Nevertheless, language difficulties may hamper his educational and occupational advancement as well as his integration in another country. Although material wellbeing may improve even considerably, immaterial welfare may suffer from cultural isolation. Implications, for the migrants and not least their families, particularly in the long term, are insufficiently known because of the paucity of relevant studies.

A study made by Professor Elina Haavio-Mannila on the basis of the material collected for the Swedish investigations on the low-income population shows that Finns in Sweden work longer hours than Swedes, and that their work is physically more strenuous, more monotonous and demands more speed. Fatigue at work impairs their health. More Finns than Swedes suffer from aches and pains, circulatory disorders, mental ill health, ortopedic disorders and fatigue. Finns are also more often absent from work for health reasons, and have to be hospitalised more frequently.

There may be numerous reasons for these phenomena, but differences in occupational structure and hence inferior working conditions are hardly without significance.

The income of Finnish immigrants is roughly as high as that of Swedes of similar sosio-economic status. The Finns have, however, poorer housing and live in more crowded conditions than the Swedes, though perhaps their housing is better than in Finland. Immigrants have fewer media of communication than Swedes. This is partly due to the language difficulty. Although they spend as much time with friends as Swedes, they have less contact with relatives and fewer hobbies. Although immigrants have since 1976 the voting rights in the municipal elections, the language barrier prevents Finns from taking part in politics. They do belong to trade unions and are nearly as active in them as Swedes of similar status, though their political activity in the trade unions is not very pronounced. But perhaps their most serious and far-reaching problem is that of their children's difficulties at school, owing to a poor knowledge of the language.

The consequences of return migration are, at least in theory, reverse to those arising from emigration. Since the studies covering also these aspects are still at an initial stage, no firm conclusions can be advanced. Nevertheless, it may be noted that also return may often be beset with problems that the repatriating person has not envisaged. For example, the wage and the level of living, especially housing conditions, may not be so good as in Sweden. Children, though they may be able to speak Finnish, often encounter linguistic difficulties at school at least for some time. Some migrants - often those who have experienced failures abroad - may not adapt themselves to Finnish conditions, either. 


\section{Prospects of migration}

In population forecasts, external migration seems to be the item that is hardest to predict. Emigration and return migration are in a way marginal elements in population changes and they depend on a complex interplay of many factors. Hence, it is not possible to present any concrete assessment of the future trends concerning emigration from and return migration to Finland. Nevertheless, it may be concluded that external migration of a certain magnitude will take place in both directions for many years to come.

Economic development and the manpower requirements exceeding domestic supply of labour in Sweden will exert a major influence on the development of Finnish emigration also in the future. It is noteworthy that Sweden could accommodate 11,000 new Finnish immigrants in 1972 in spite of the recordbreaking unemployment in the country. Hence, it is likely that Sweden will experience shortages of labour also in the future. Especially for less-esteemed jobs requiring little skill it will be difficult to find domestic labour despite all the efforts to mobilise manpower reserves. This conclusion was shared by the Swedish Commission on Immigration, which reckoned with the continuation of immigration also in the future. However, no numerical forecasts were made by the Commission in its final report of 1974 .

The variation in the employment situation in Sweden may affect return migration, too. Returns have in fact been decreasing since 1971; the excess of return in 1972 and 1973 was largely due to the fact that emigration declined even faster. Since emigration has been smaller in 1971-74 than in 1969-70, the base for return migration has consequently become smaller, too.

Since the employment situation in Finland is not without significance for emigration, it is worth noting that the present, rather unfavourable situation in the Finnish labour market differs substantially from that in 1967-69, i.e. before the mass emigration in 1969-70. Since 1972 the unemployment benefit system covers practically all the unemployed, and also the benefits are greater than before. Therefore, the "push» for employment reasons might be significantly smaller than at the end of the $1960 \mathrm{~s}$. Thanks to the improving employment prospects for the late 1970 s, there is reason to expect return migrations on a significant scale, especially as special measures have been introduced to help returning Finns to find work and housing and to overcome other initial difficulties in the home country.

\section{References}

The present review is primarily based on my preliminary report Migrations between Finland and Sweden from 1946 to 1974, A Demographic Analysis (Ministry of Labour, Helsinki, 1975) and my fourth SOPEMI report to the OECD, Migrations from and to Finland in 1975 (Ministry of Labour, Helsinki, 1976). Both reports make extensive use of the official migration statistics of Finland and Sweden, published and unpublished, and of a number of Finnish and Swedish research reports. The sources are specified in the first-mentioned report. 